\title{
Evaluation approach in the practice of sustainability from cultural landscape perspective: a case study of Masjid Kampung Kling, Malacca
}

\begin{abstract}
The purpose of this paper is to view sustainability practice from the perspective of cultural landscape by looking at Masjid Kampung Kling, Malacca. The selected mosque is a traditional building gazetted under National Antiquity Act (2005) and is located within the area of UNESCO World Heritage Site. A qualitative case study was used in uncovering the practice of sustainability. The cultural landscape approach has guided the study by questioning the meanings embedded within the traditional mosqueôs features thus providing a new angle of viewing the landscape as a social expression of symbols, icons, and metaphors. Concepts of sustainability and cultural landscape were reviewed for acquiring the sense of connection with each other. As for evidence, data was collected from several series of observation and interviews. Masjid Kampung Kling can be seen as a sub-cosmic from an enormous multi-culture of Malacca. Findings from the study suggested that the mosque has the portrayal of practical sustainability practice by both the contextual mean and testimonial proof. The sustainability practice can be viewed from three significance values of cultural landscape of the mosque namely (1) history (2) architecture and (3) archaeology. Current management should recognise Masjid Kampung Kling and other traditional mosques in general, for having the potential to present sustainability from cultural landscape perspective. Though Masjid Kampung Kling is already known as tourist attraction, concept improvement in the context of tourism will definitely add more values especially for academic and learning purpose.
\end{abstract}

Keyword: Sustainability; Cultural landscape; Case study; Masjid Kampung Kling 